\title{
Analysing the risk of climate change using an irrigation demand model
}

\author{
Roger N. J ones* \\ CSIRO A tmospheric Research, Private Bag No. 1, Aspendale, Victoria 3195, Australia
}

\begin{abstract}
Due to the high degree of uncertainty accompanying projections of greenhouse-induced climate change, specific impacts cannot be predicted with any accuracy. At best, a range of projected climate change bounded by its high and low extremes can be used to produce a range of impacts, results that are often too broad to be of practical use in planning for adaptation and mitigation. However, by addressing outcomes in the initial stages of an impact assessment through the construction of user-defined thresholds, it is possible to identify outcomes that should either be avoided, in the case of a negative impact, or aimed for, in the case of a positive impact. By quantifying these thresholds as functions of key climatic variables, and creating projections for these variables that take account of a comprehensive range of quantifiable uncertainties, the risk of threshold exceedance can be analysed. This information can then be used in a risk assessment to identify windows for adaptation, describing the timing and degree of adaptation needed to prevent 'dangerous' climate change occurring for a particular activity. This procedure is illustrated through the use of an irrigation demand model for perennial pasture, based on data collected from a farm in northern Victoria, Australia. Seasonal wateruse is used to estimate an annual farm cap of $12 \mathrm{MI} \mathrm{ha}^{-1}$ based on the annual water right. The exceedance of this farm cap in $50 \%$ of years is taken to represent a critical threshold beyond which the farmer cannot adapt. The method of risk analysis utilises projected ranges of regional rainfall and temperature change, combined with a sensitivity analysis, to construct risk response surfaces. M onte Carlo sampling is used to scale $100 \mathrm{yr}$ of weather-generated data to calculate the probability of the annual farm cap being exceeded across ranges of temperature and rainfall change projected at $10 \mathrm{yr}$ intervals from 2000 to 2100. Based on the model projections of changing water demand, some degree of adaptation is indicated by 2030 , although the theoretical critical threshold is not approached until 2050. This procedure represents a considerable advance in 'bottom up' studies where the impact on a specific activity is being addressed. It provides a basis for the planning of adaptation measures and can potentially contribute to the assessment of dangerous climate change as required by the UN Framework Convention for Climate Change.
\end{abstract}

KEY WORDS: Climate change - Impact assessment · Risk analysis · Irrigation

\section{INTRODUCTION}

Global climate is a complex, adaptive system influenced by biophysical relationships linking earth, ocean and atmosphere. Like most complex, adaptive systems climate is metastable, exhibiting aspects of both regular and chaotic behaviour. Over the last decade, the representation of regular climatic behaviour has been improved (IPCC 1996a) through better physics and higher resolution within global climate

*E-mail: roger.jones@dar.csiro.au models (GCMs). Such improvements have also led to better simulations of chaotic behaviour, such as shortterm climate variability and the manifestation of EI Niño-like behaviour (eg. Knutson et al. 1997, Wilson \& Hunt 1997, Timmermann et al. 1999).

Despite these advances, it is becoming clear that climate models will never be able to provide a singular prediction for future climate. Even if the pathways for greenhouse gas emissions were fully known, some uncertainty within the climate system is fundamental, yielding a range of predictions rather than a single figure. This is especially true for representations of regional climates. There is no consensus amongst cli- 
mate modellers about how close modelling is to reaching a threshold of uncertainty that can be represented by climate models, how far current estimates of uncertainty can be reduced and what time-scale may be required for this to be achieved (cf. Mahlman 1997).

The uncertainty within climate scenarios flows through to the prediction of impacts. If a single scenario is used to model a particular impact, the results may be fairly precise but are conditional on that single scenario, and are unlikely to be representative of other possible futures. Conversely, if the major uncertainties are incorporated into a range of projected regional climate change (eg. CSIRO 1996), when the high and low ends of that range are applied to impact analysis, the resulting range of outcomes is often too large to be of real use for planning or policy purposes.

In summarising the results of impact studies published to 1995, the Working Group II Second Assessment Report of the International Panel on Climate Change (IPCC 1996b) concluded that many ecological and socio-economic systems were at risk from climate change. However, to date, research has been unable to provide the strategies needed to address the 2 major issues raised in the United Nations Framework Convention on Climate Change (FCCC) regarding climate change impacts, namely those of mitigation and adaptation. Mitigation strategies aim to stabilise greenhouse gas concentrations in the atmosphere at levels preventing 'dangerous' anthropogenic interference with the climate system, while adaptation strategies recognise that some climate change is inevitable, and that some systems sensitive to climate will prove to be vulnerable, requiring adaptation measures.

As both of these strategies deal with the identification and avoidance of risk, a framework is needed to link levels of climate change with levels of impacts, through the use of risk assessment. This paper describes a method of risk analysis that calculates conditional probabilities of exceedance of impact thresholds under climate change. An example, using a simple irrigation demand model, is used to illustrate the technique, which forms part of a framework for the risk assessment of individual or related activities under climate change.

\section{RISK ANALYSIS TOOLS}

\subsection{Using and combining ranges of uncertainty}

Climate change scenarios and projections provide the input into impact models. Excluding methods that apply downscaling, these inputs can be classified as: (1) Scenarios based on direct GCM output. (2) Projections based on scaled GCM -derived patterns of climate change from 1 or more GCMs expressed as a range with an upper and lower limit.

The major differences between these 2 types is that direct output is subject to the sensitivity and forcing within the individual GCM, while projected ranges preserve local patterns of change while being scaled for different assumptions of climate sensitivity and greenhouse gas emissions. The method of scaling was first suggested by Santer et al. (1990) and can be used to scale a single GCM or a suite of GCM s (Rotmans et al. 1994, Whetton et al. 1996). Strictly speaking, by definition a scenario is a plausible future outcome that has no further degree of probability attached. Therefore, a projected range of climate that contains a level of probability can no longer be defined as a climate scenario (J ones 1999).

To obtain a more comprehensive range of uncertainty, Pittock (1993) recommends projected ranges of regional climate from a suite of GCMs as being more appropriate for impact assessment. This has seen the development of the CSIRO regional scenarios for Australia (CSIRO 1992, 1996, Whetton et al. 1996) and their application in impact studies (Schreider et al. 1996, Whetton et al. 1996, Hassall \& Associates 1998). As mentioned in the 'Introduction', the broad outcomes these impact studies produce have limited utility.

The major uncertainties in projected ranges of regional climate arise from 3 main sources: (1) Emission scenarios, influenced by economic activity, population growth and technology. (2) Global climate sensitivity, measured by the sensitivity of global climate models to greenhouse gas forcing. (3) Regional variability, which occurs between models as different regional responses, and within models through chaotic behaviour and modes of climate variability, especially multi-decadal variability.

A number of other uncertainties, such as ranges of uncertainty in radiative forcing and greenhouse gas exchange between the atmosphere, biosphere and oceans, can be acknowledged but are not commonly incorporated into ranges. However, there is a significant amount of research attempting to quantify and incorporate these uncertainties into estimates of future climate.

When climate change information is applied to impact assessment, additional impact-related uncertainties arise. If the vertical integration of physical through to socio-economic impacts is sought, the incorporation of these broad ranges of uncertainty into the impact analysis can produce a very large range of possible impacts, sometimes termed the cascade of uncertainties or uncertainty explosion (Henderson-Sellers 1993; Fig. 1).

The Climate Impact Group of CSIRO Atmospheric Research has advised A ustralian impact researchers to use the upper and lower limits of regional projections in impact studies for 2 reasons: (1) To avoid central 


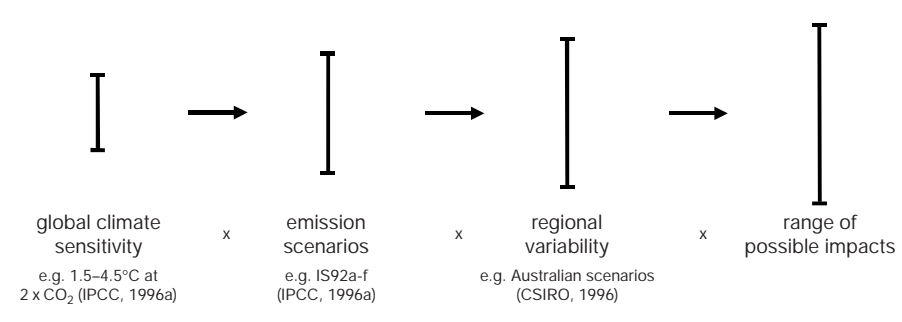

Fig. 1. Range of major uncertainties involved in impact modelling at a particular time, showing the uncertainty explosion caused when these ranges are multiplied to encompass the full range of future possibilities

tendencies where a 'best bet' estimate is applied with what resembles a statistical error range, which is then discarded as the single, central number is retained. A unique outcome for the future, without an accompanying range of uncertainty, looks too much like a prediction. (2) Because the probability distribution function of these ranges of uncertainty is unknown, the use of upper and lower limits leads to the default assumption of uniform probability, which persists through all the steps of the impact analysis. This assumption of uniformity is likely to be conservative except where the true probability distribution function is L- or M-shaped.

However, as classical statistics show, if the steps within the uncertainty explosion are each assumed to have a uniform distribution and are independent of each other, when they are multiplied together the resultant distribution will not be uniform but will peak around an average value.

This is demonstrated in Fig. 2, which shows the resultant probability when 2 component ranges of

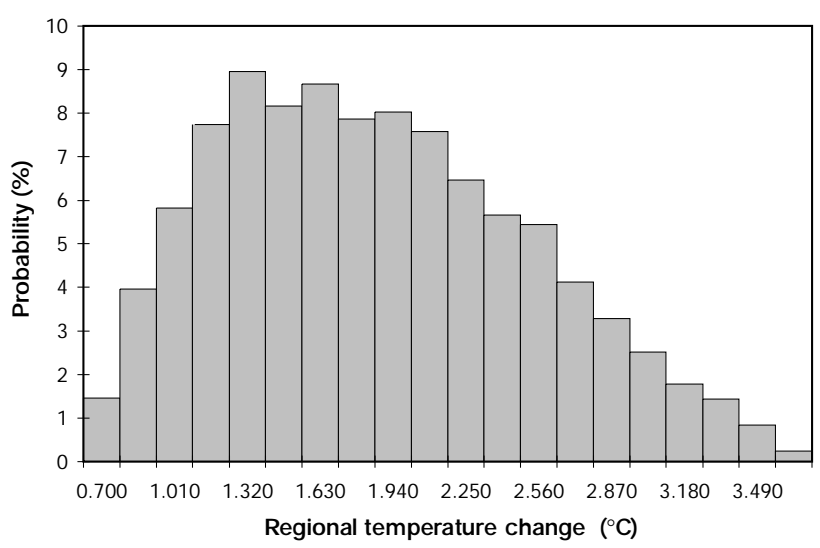

Fig. 2. Probability distribution of a projected range of regional warming in 2070 for inland Australia from CSIRO (1996), showing the probability of occurrence for $5 \%$ increments within the total range of 0.7 to $3.8^{\circ} \mathrm{C}$, based on Monte Carlo sampling. The component ranges of 0.7 to $2.1^{\circ} \mathrm{C}$ (global warming) and 1.0 to $1.8^{\circ} \mathrm{C}$ (local warming per degree global warming) are randomly sampled 5000 times and multiplied to obtain the distribution shown uncertainty with uniform probability are combined. The range for global warming in 2070 of 0.7 to $2.1^{\circ} \mathrm{C}$ (IPCC 1996a) is multiplied by estimates for inland Australia of 1.0 to $1.8^{\circ} \mathrm{C}$ local warming per degree of global warming (CSIRO 1996), and the resultant range of project regional warming is 0.7 to $3.8^{\circ} \mathrm{C}$. The regional range of local warming per degree of global warming is constructed from the scaled values of a suite of 5 GCM s as described by Whetton et al. (1996). Assuming the independence of both these ranges, when Monte Carlo sampling is carried out, the probability distribution produced is not uniform but is peaked (Fig. 2). Although the range expands, as in Fig. 1, the central values are far more probable than the extremes.

The application of known probability distributions has been used to solve problems in many fields, such as economics, insurance and gambling (Bernstein 1996), where, by applying historical data, statistical methods are used to forecast the probability of a particular set of outcomes. Under climate change, projections of climate derived from physical models are used in lieu of a statistically represented history. This technique is used here to calculate projected ranges of regional climate for the key climatic variables that form the input to the irrigation demand model.

To calculate probabilities from combined ranges of uncertainty as in Fig. 2, several conditions must be met: (1) The component ranges of uncertainty must be independent if random sampling is to be used. If factors show dependence, this must be correctly applied to the sampling method. (2) The major factors influencing the impact under analysis should be incorporated into the methodology wherever possible. (3) The full range of quantifiable uncertainty, or a comprehensive range with adequate justification, must be applied within each step of the process to avoid the underestimation of risk through the use of truncated ranges. (4) The probability density function of each range of uncertainty must be explicitly acknowledged.

The application of this method to projected ranges of climate change is described in Section 3.5.

\subsection{Impact thresholds}

To assess risk, climate impacts are explored to determine appropriate thresholds. An impact threshold is a generic term for any threshold that can link an ecological or socio-economic impact to a climatic state or states (Pittock \& J ones 1999). Impact thresholds can be grouped into 2 main categories: biophysical thresholds that mark a physical discontinuity on a spatial or temporal scale, and behavioural thresholds, where reaching a particular state triggers a change in behaviour in the form of a social or economic outcome (R. A. Warrick pers. comm.). 
Threshold events may signal a distinct change in conditions or a step on a scale that has been nominated as significant (i.e. a benchmark). Climatic thresholds include frost, snow and monsoon onset. Biophysical thresholds represent a distinct change in conditions, such as the drying of a wetland, floods, breeding events, etc. Behavioural thresholds are set by benchmarking a level of performance, e.g. the yield per unit area of a crop in weight, volume or gross income (J ones \& Pittock 1997). An example of an operational threshold is described in Campbell et al. (1997), where the identification of sustainable thresholds for grazed grassland systems under global change is recommended.

Critical thresholds are a special category, being assessed to determine the point at which the risk of an impact becomes 'dangerous' (cf. Parry et al. 1996). This assessment involves placing values on processes and/or outcomes. The assumptions behind such valuations should ideally be transparent and should be understood by all those affected. Pittock \& J ones (1999) argue that stakeholders should ideally be involved in the process of determining user-defined thresholds especially if they are to be involved in planning or implementing adaptation options.

As impacts differ within sectors and regions and vary over time, critical thresholds for different activities and localities will not be reached at the same time or with the same rate of climate change. The concept of what is critical may differ between various groups and may also change over time in response to new information, to adaptive capacity or to changes in social and political perspectives. Climate scenarios can be used to determine when and where 'dangerous' thresholds are reached in various sectors (Parry et al. 1996). This can then be related back to rates of greenhouse gas emissions.

\section{MODEL APPLICATION AND RESULTS}

\subsection{Model description}

To show how the methodology described in this paper can be used, a simple irrigation demand model was constructed. Data from the M odel Farm at Kerang, northern Victoria, was used to build a simple model estimating irrigation demand on a perennial pasture dominated by white clover Trifolium repens and perennial ryegrass Lolium perenne. Approximately 24 ha of flood-irrigated pasture are grazed by beef cattle with some hay produced every spring. The irrigation season is August 1 to April 30. Maximum and minimum temperature, rainfall and Class-A pan evaporation are recorded at an official weather station situated on the property; observations cover the period 1990 to 1996.

An earlier model estimating water-use during the irrigation seasons 1989-90 to 1995-96 closely followed evaporative demand rather than a regulated supply. Based on rainfall, pan evaporation data and records of water consumption for those seasons, that earlier model estimated seasonal irrigation water-use on the farm to within $\pm 4 \%$, showing that irrigation management from 1989 to 1996 was remarkably consistent (J ones 1997). Irrigation water-use on the Model Farm was also correlated with the total Cohuna Irrigation District consumption from 1976 to 1996 and the combined Cohuna-Kerang District consumption from 1987 to 1996 at 0.84 and 0.88 respectively (Fig. 3). This shows that irrigation demand on the Model Farm is representative of irrigation demand at the district level and implies that, for the past $20 \mathrm{yr}$, regional irrigation demand has been largely driven by evaporative demand.

A simple box-type irrigation demand model based on the relationships described by Boughton (1966), and run on a daily time-step, was constructed to simulate irrigation demand under climate change conditions. The model uses rainfall and potential evaporation as inputs, and requires estimates of the field capacity of the soil, wilting point and threshold soil moisture for Trifolium repens (the dominant summer-growing pasture plant). When soil moisture falls below the estimated wilting point for $\mathrm{T}$. repens, irrigation is automatic and equivalent to a $75 \mathrm{~mm}$ rainfall. This fills the soil water reservoir and allows for $25 \mathrm{~mm}$ of water lying on the paddock after irrigation. Any subsequent rainfall exceeding this threshold is converted into runoff.

The model was separated into 4 separate paddock modules allowing for differences in soil and pasture types across the farm. Values for field capacity, wilting point and threshold soil moisture were calibrated for

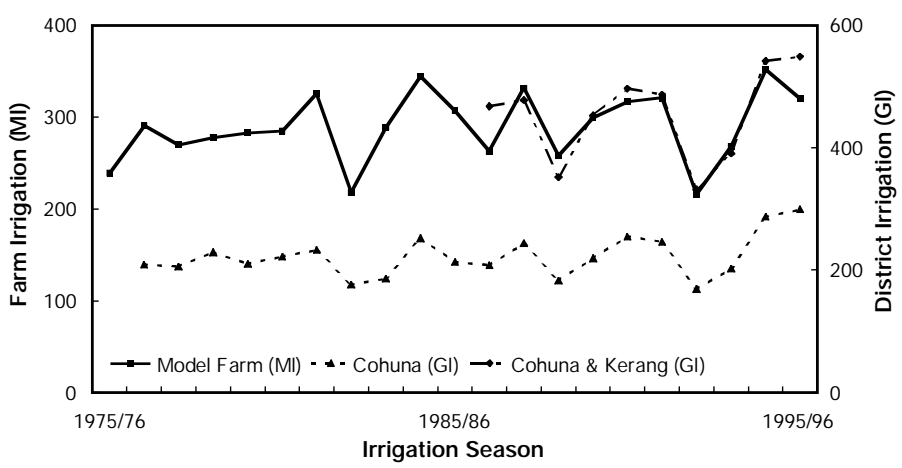

Fig. 3. Seasonal irrigation water consumption on the Model Farm in megalitres (MI, 1975 to 1996), Cohuna Irrigation District in gigalitres (GI, 1976 to 1996) and the combined Cohuna-Kerang District (1987 to 1996) 
the 1995-96 season, when the timing and volume of irrigation for individual paddocks was available. Although this model is less accurate than the more empirical model used in J ones (1997), it is more physically realistic. The results are less precise than historical irrigation water-use, because the model irrigates automatically in $75 \mathrm{~mm}$ increments once a given threshold soil moisture is reached, whereas farmer behaviour is more finely tuned.

A single paddock module containing the weather station was chosen for simulations under climate change. As demand-based irrigation from the Model Farm is closely correlated with district water-use, this paddock-scale irrigation model designed to model the behaviour of the irrigator is also assumed to represent irrigation demand at the district scale $\left(10^{3} \mathrm{~km}^{2}\right)$.

\subsection{Key climatic variables}

The key climatic variables for measuring irrigation demand are rainfall and potential evaporation. Interannual climate variability is al so important for calculating statistics for irrigation demand, so a long sequence of these variables is required. The LARS weather generator utilising a series approach to simulate long dry and wet-day sequences (Racsko et al. 1991) was used to generate a $100 \mathrm{yr}$ sequence of daily maximum and minimum temperatures and rainfall based on data from 1990 to 1996. Artificially generated potential evaporation was unavailable, so monthly regression relationships of daily evaporation against maximum temperature for the period 1990 to 1996 were used to estimate evaporation from the weather-generated maximum temperature.

Both monthly rainfall and temperature averages and standard deviation were well simulated on a monthly basis in the model according to t-test and Ftest statistics, with none falling below a $5 \%$ probability level, and were compatible with long-term means from the nearby Kerang station (1882 to 1997). The simulation of interannual variability of rainfall was also adequate up to the 10th and 90th percentile, although the highest and lowest extremes for rainfall from the longer Kerang record were not reproduced. This result is consistent with the limitation reproduction of annual variability shown by this and other weather generators (Semenov et al. 1998). Evaporation regressed from temperature was substituted into the model for 1990 to 1996 and compared with the results produced using the observed evaporation data. The results were identical, although this is partly due to the stochastic nature of the model, which irrigates in $75 \mathrm{~mm}$ increments and thus is insensitive to small changes in inputs.

\subsection{Impact thresholds}

Two thresholds were chosen for measuring changes to irrigation demand under climate change. The first is termed the farm cap and is the irrigation allocation for the Model Farm during a typical irrigation season. During the 1970s and 1980s, irrigation demands were met by allocations exceeding the nominal water right, so that in most years evaporative demand could be met with few restrictions. The only restrictions imposed during this period were in response to the 198283 drought. The largely unrestricted allocation of irrigation water supply has led to a gradual increase in irrigation allocations basin-wide. This increase has been recognised as a threat to the overall health of the system and to the security of water supply in the long term (Cox \& Baxter 1996).

The water available to irrigators in the State of Victoria has been capped at the 1993-94 level (MWEC 1997). This translates to a farm cap, which is set at $200 \%$ of the annual water right per farm (G. O. J ones pers. comm.). In most years, the cap will be sufficient to meet irrigation demand, but in years when demand is high and supply is low the cap will be lowered, increasing the likelihood of exceedance. Farmers will have to adapt through measures such as decreasing the area under irrigation, destocking, importing supplementary feed, or by introducing more efficient irrigation systems.

Using the paddock-scale irrigation model, and scaling up to the average area under irrigation on the M odel Farm, this cap was set at $12 \mathrm{MI} \mathrm{ha}^{-1} \mathrm{yr}^{-1}$. On the basis of past management, demand above that level would now require some form of adaptive behaviour, since meeting that demand would exceed the farm cap. Extra irrigation water can be purchased but at spot market prices likely to exceed the regular price.

During dry years, any shortfall in irrigation supply may result in the $200 \%$ cap being reduced. This cannot be factored into the current model, as it requires estimation of supply from the upper catchments and of the behaviour of the irrigation water storage and supply system. For the current example, it is assumed that supply will only fall short during those years when irrigation demand is high. Based on past irrigation figures, this is a reasonable first-order assumption.

Farmers are adapting to the imposition of farm caps through on-farm measures such as diversifying to higher return activities and increasing irrigation efficiency. However, if the frequency of irrigation demand exceeding the farm cap increases due to changes in rainfall and evaporation, there will be a level of exceedance above which the farmer cannot adapt. This stage is defined here as the critical threshold for irrigated pasture under grazing. The actual level of ex- 
ceedance for this threshold is unknown and would require further research that takes into account such factors as levels of irrigation supply, productivity and gross economic return. For purposes of example, the critical threshold is set at $50 \%$, i.e. if the farm cap is exceeded at a frequency of 1 year in every 2 , then it is assumed that this activity can no longer continue.

The farm cap of $12 \mathrm{MI} \mathrm{ha}^{-1}$ provides a threshold above which some adaptation is required. For $100 \mathrm{yr}$ of weather-generated data based on the observed 1990 to 1996 climate data, the cap is exceeded $5 \%$ of the time. This model therefore offers the following thresholds for further investigation: (1) a farm cap of $12 \mathrm{MI} \mathrm{ha}^{-1}$, whose frequency of exceedance can be estimated using a $100 \mathrm{yr}$ artificial record of climate; (2) a critical threshold where the frequency of irrigation demand above the farm cap exceeds the ability of the farmer to adapt, jeopardising that activity. For this example, this limit is assumed to be $50 \%$, where the farm cap is exceeded by irrigation demand 1 year in every 2 .

\subsection{Sensitivity analysis}

The next step in the analysis is to quantify the sensitivity of the 2 thresholds to the key climatic variables. Under current climate, the model simulates irrigation demand exceeding the farm cap of $12 \mathrm{MI} \mathrm{ha}^{-1}$ in $5 \%$ of years. This is comparable with the estimate of M urrayGoulburn Water, the supplier of irrigation water to the region, that supply can be met in $97 \%$ of years ( $E$. J ones pers. comm.). The historical data suggests that these years will coincide, as irrigation demand is generally higher than average during drought years.

A sensitivity matrix was calculated for temperature increases ranging from 0 to $6.5^{\circ} \mathrm{C}$ and rainfall changes ranging from +30 to $-30 \%$. Evaporation was calculated from adjusted maximum temperature using the regression relationships described earlier. The resulting sensitivity matrix is shown in Fig. 4, where the frequency of exceedance for the annual $12 \mathrm{MI} \mathrm{ha}^{-1}$ farm cap ranges from a few percent to over $100 \%$.

The $50 \%$ line is the critical threshold described above. It requires a reasonable degree of climate change to be reached, e.g. average temperature would have to rise about $2.5^{\circ} \mathrm{C}$ with current rainfall held constant.

\subsection{Climate change probabilities}

Ranges of projected global warming from IPCC (1996a) and projected regional temperature and rainfall in northern Victoria from CSIRO (1996) were sub-

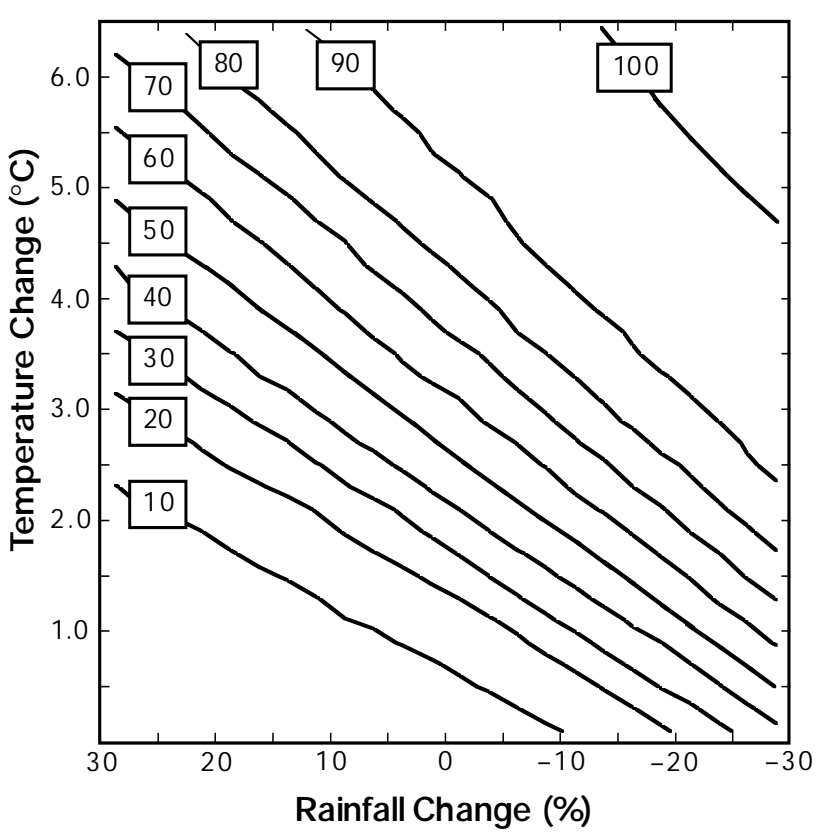

Fig. 4. Sensitivity matrix showing the probability of exceedance of the farm cap of $12 \mathrm{MI} \mathrm{ha}^{-1}$ for an irrigated pasture in Northern Victoria, relative to temperature and rainfall changes (see text)

jected to the techniques described in Section 2.1. Each component range of uncertainty was assumed to have a uniform probability distribution, and regional temperature change and rainfall change were assumed to be independent of each other, which is the default assumption in CSIRO (1996). For the temperature scenarios, 2 ranges of uncertainty, global warming and regional uncertainty, were randomly sampled then multiplied repeatedly, to obtain a non-uniform distribution of regional temperature change. The range of projected global warming incorporates the IPCC-estimated range of climate sensitivity and the IS92a- $f$ emission scenarios (Table 1, columns 1 and 2). Regional uncertainty is expressed as local warming per degree of global warming that has been obtained from a suite of GCMs (Table 1, columns 3 and 4). This process was repeated over $10 \mathrm{yr}$ intervals from 2000 to 2100 and the resultant probability distribution for regional warming in 2070 is shown in Fig. 2.

Rainfall was calculated slightly differently. Each time global warming was randomly sampled for calculating local temperature change, the same value was used to calculate local rainfall change. Local rainfall change was divided into separate ranges for summer and winter, expressed as a percentage change per degree of global warming. Global warming was used to scale the possible range of rainfall change, to ensure that values anomalous to that degree of warming were not sampled. The ranges given in Table 1 
(columns 5 and 6 [summer], and 7 and 8 [winter]) are the maximum range that can then be randomly sampled. Therefore, the procedure was to use the same sample of global warming for both temperature (as above) and rainfall, to use that sample to define the range of local rainfall change for both summer and winter, to sample randomly within both ranges and to average for an annual value. Note that this technique assumes that summer and winter changes are independent of each other and that no weighting in the averaging process is given for differences in the summer/winter totals.

The results were tallied in matrices of rainfall and temperature change constructed with an average sampling density of about 100 samples bin $^{-1}$ ranging in size from 9 bins in 2000 to 400 bins in 2100. The percentage frequency of outcomes in each bin was calculated and summed from the most frequent to the least frequent to provide cumulative probability plots (Fig. 5).

The cumulative probability plots in Fig. 5 show that, rather than being a large rectangle of uniform probability described by projected ranges of rainfall and temperature as in CSIRO (1996), some outcomes are more likely than others. For instance, combinations of extreme changes in both temperature and rainfall are unlikely. Fig. 5 shows that over time the projected range with a low probability of occurrence $(<5 \%)$ occupies a larger proportion of the uncertainty space. This shows that a large proportion of the uncertainty created by combining results from different GCMs can potentially be managed through simple statistical techniques. The next section shows how the combination of climate change probabilities, impact sensitivity analysis and impact thresholds can be used to analyse risk.

\subsection{Risk analysis}

Risk analysis is carried out by measuring the exceedance of a particular threshold with reference to projections of key climatic variables. The result is depicted using a risk response surface, combining a sensitivity diagram as in Fig. 4 with climate probability plots as in Fig. 5. The probabilities of all climates occurring above a particular threshold can then be totalled to estimate the risk of exceedance of that threshold.

Risk analyses were carried out for irrigation demand at $10 \mathrm{yr}$ intervals between 2000 and 2100 . The resultant risk response surfaces for 2030 and 2070 are shown in Fig. 6. In 2030, the annual threshold will be exceeded in $<10$ to $20 \%$ of years under most climates. By 2070 , this range extends from 10 to $80 \%$. The critical threshold lies well above the projected ranges of climate change in 2030 but by 2070 is exceeded by almost one-quarter of the projected climates.

The next step is to calculate how often the farm cap may be exceeded at specified times in the future. This is carried out by totalling the probability of all climates falling below a certain level of farm cap exceedance. For example, in Fig. 6, the percentage frequencies of projected climate lying below a contour representing a level of exceedance are totalled. Examples for the years 2030 and 2070 are plotted in Fig. 7. In 2030 the annual probability that the farm cap will be exceeded lies between 10 and $20 \% .90 \%$ of all climates (the $x$ axis) will see the farm cap exceeded at least 1 in every $10 \mathrm{yr}$ (the $\mathrm{y}$-axis), while in $95 \%$ of all climates the annual farm cap will not be exceeded by more than 1 in every $5 \mathrm{yr}$. In 2070, this range of exceedance is much larger, where it is possible for the farm cap to be exceeded from 10 up to $80 \%$ of years.

Table 1. Upper and lower bounds for scenarios used in climate probability sampling. The temperature columns list the global range and the local range (the global range multiplied by the local change per degree of $1.0-1.8^{\circ} \mathrm{C}$ ). Rainfall lists the summer and winter ranges separately, which are produced by multiplying upper and lower limits of rainfall (\% change per degree of global warming: -5 to $+10 \%$ for summer and -10 to $+2.5 \%$ for winter) by the upper limit of global temperature. The method is based on CSIRO (1996)

\begin{tabular}{|c|c|c|c|c|c|c|c|c|c|c|}
\hline \multirow[t]{2}{*}{ Year } & \multicolumn{4}{|c|}{ Temperature $\left({ }^{\circ} \mathrm{C}\right)$} & \multicolumn{6}{|c|}{ Rainfall (\%) } \\
\hline & $\begin{array}{c}\text { Global } \\
\text { low }\end{array}$ & $\begin{array}{l}\text { Global } \\
\text { high }\end{array}$ & $\begin{array}{l}\text { Local } \\
\text { low }\end{array}$ & $\begin{array}{l}\text { Local } \\
\text { high }\end{array}$ & $\begin{array}{c}\text { Summer } \\
\text { low }\end{array}$ & $\begin{array}{l}\text { Summer } \\
\text { high }\end{array}$ & $\begin{array}{c}\text { Winter } \\
\text { low }\end{array}$ & $\begin{array}{l}\text { Winter } \\
\text { high }\end{array}$ & $\begin{array}{c}\text { Annual } \\
\text { low }\end{array}$ & $\begin{array}{c}\text { Annual } \\
\text { high }\end{array}$ \\
\hline 2000 & 0.1 & 0.2 & 0.1 & 0.4 & -1 & 2 & -2 & 0.5 & -1.5 & 1.5 \\
\hline 2010 & 0.2 & 0.4 & 0.2 & 0.8 & -2 & 4 & -4 & 1 & -3 & 3 \\
\hline 2020 & 0.3 & 0.6 & 0.3 & 1.1 & -3 & 6 & -6 & 1.5 & -4.5 & 4.5 \\
\hline 2030 & 0.4 & 0.8 & 0.4 & 1.5 & -4 & 8 & -8 & 2 & -6 & 5 \\
\hline 2040 & 0.5 & 1.1 & 0.5 & 2.0 & -5.5 & 11 & -11 & 3 & -9 & 7 \\
\hline 2050 & 0.5 & 1.3 & 0.5 & 2.4 & -6.5 & 13 & -13 & 3.5 & -10 & 10 \\
\hline 2060 & 0.6 & 1.7 & 0.6 & 3.1 & -8.5 & 17 & -17 & 4 & -13 & 11 \\
\hline 2070 & 0.7 & 2.1 & 0.7 & 3.8 & -10.5 & 21 & -21 & 5 & -16 & 14 \\
\hline 2080 & 0.8 & 2.5 & 0.8 & 4.5 & -12.5 & 25 & -25 & 6 & -19 & 16 \\
\hline 2090 & 0.8 & 3.0 & 0.8 & 5.4 & -15 & 30 & -30 & 7.5 & -23 & 19 \\
\hline 2100 & 0.9 & 3.5 & 0.9 & 6.3 & -17.5 & 35 & -35 & 9 & -28 & 22 \\
\hline
\end{tabular}


The critical threshold, where the farm cap is exceeded in $50 \%$ or more years, is not approached in 2030, but is exceeded by $23 \%$ of climates by 2070 .

\subsection{Windows of adaptation}

Having established a relationship between the probability of climate change and the probability of a
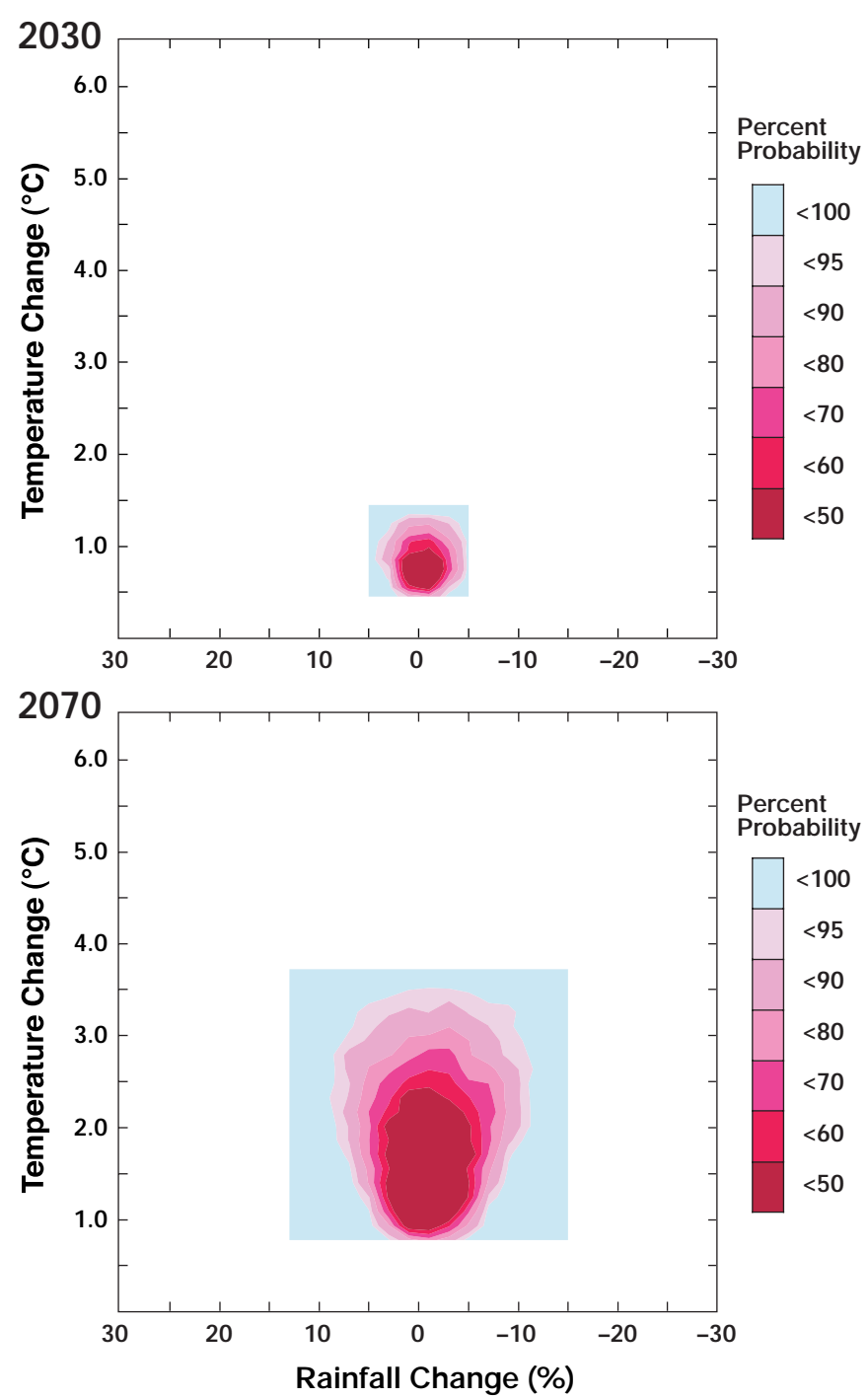

Fig. 5. Cumulative probability plots for projected ranges of regional climate for 2030 and 2070 in northern Victoria from CSIRO (1996). Temperature was sampled randomly within both the global and local ranges, which were then multiplied. The upper and lower limits of the change per degree range for summer and winter rainfall shown in Table 1 were multiplied by the randomly sampled global temperature. The adjusted summer and winter ranges were then randomly sampled also. The probability plots were calculated by cumulatively adding percentage frequency in order from the most to the least likely for all gridpoints
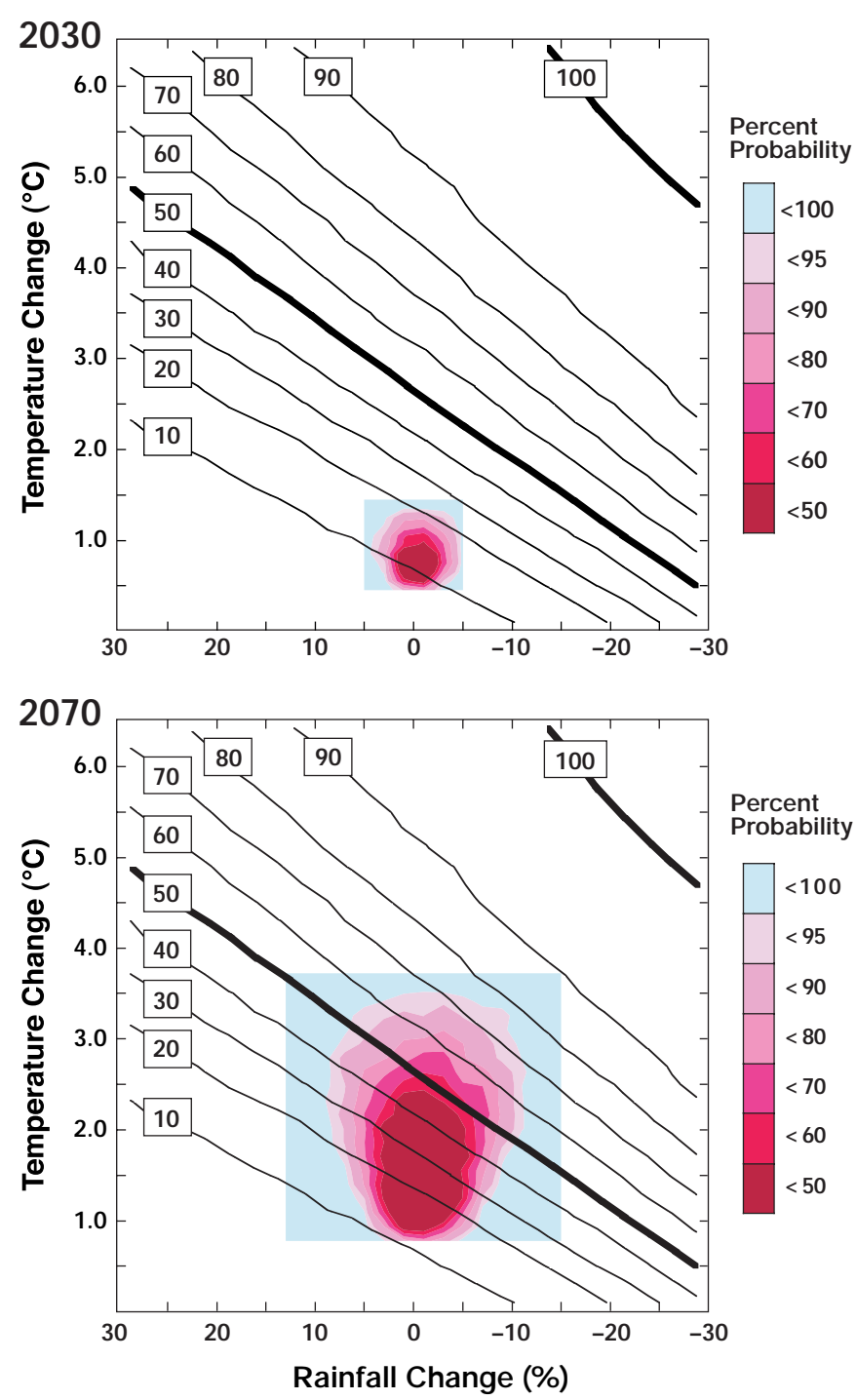

Fig. 6. Risk response surface incorporating cumulative probability plots for regional climate with the probability of exceedance of the farm cap for annual irrigation demand for 2030 and 2070 in northern Victoria. The cumulative probability plots are as shown in Fig. 4 and the threshold exceedance plots are as shown in Fig. 3

threshold being exceeded for a particular activity, the topic of risk needs to be engaged. If an assessment deems the risk being faced to be worthy of a response, it will need to be managed. Under the FCCC, there are 2 major areas for the management of climate change: mitigation and adaptation. Adaptation at the local or regional scale is the most appropriate response for particular activities where the risk of impacts is assessed to be sufficiently high. Mitigation is currently being addressed at the national and international level and relates to the stabilisation of emissions to prevent dangerous climate change occurring.

Section 3.3 identified a critical threshold above which a farmer involved in irrigating pastures for 


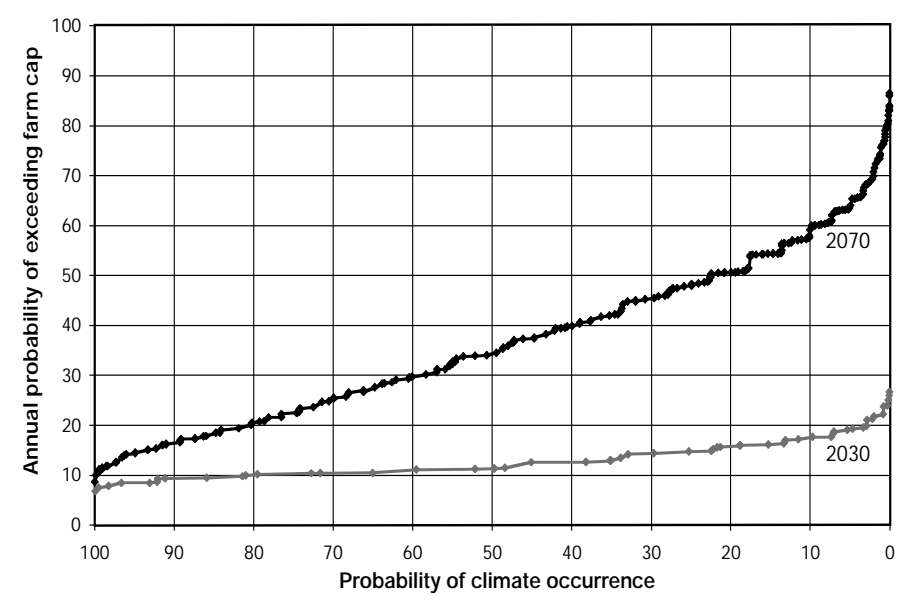

Fig. 7. Threshold-probability plot showing the relationship between the probability of threshold exceedance (the farm cap of $12 \mathrm{MI} \mathrm{ha}^{-1}$ ) and the probability of climate moving beyond that threshold in 2030 and 2070

beef production could not adapt. If the annual irrigation demand exceeds $12 \mathrm{MI} \mathrm{ha}^{-1}$ in more than $50 \%$ of years then the activity is no longer viable. In reality, it would become uneconomic long before this, and other activities would become more viable in relative terms.

Fig. 7 shows that in 2070 the critical threshold of $50 \%$ will be exceeded in $23 \%$ of possible climates. The questions that need to be asked regarding risk assessment are: Does a $20 \%$ probability of a critical threshold being reached in 2070 warrant concern? Do lesser rates of exceedance require adaptation before that date?

Such questions may be investigated in several ways. Rational frameworks can be used, where risk is quantified according to a given method (e.g. cost-benefit analysis, where cost is multiplied by probability to derive an index of risk). Another method is to present the results of the analysis to the relevant stakeholders and, using a combination of objective and subjective methods, assess the risk faced by that particular activity through consensus.

One way of viewing the problem is to assess the relationship between the critical threshold and climate over time through identifying windows of adaptation. Such a window is the period between an assessment and the point at which there is a risk of a critical threshold being exceeded. The window of adaptation has a temporal, just described, and a relational aspect. The degree of adaptation required is measured by the difference between current outcomes and those linked to the critical threshold.

Fig. 8 shows the probability of exceedance of the critical threshold for irrigation demand at $10 \mathrm{yr}$ inter- vals from 2000 to 2100 . This probability ranges from only $1 \%$ in 2040 to $63 \%$ by 2100 . The nominated critical threshold of $50 \%$ exceedance of the farm cap does not exceed a $10 \%$ probability until after 2060 , indicating a large potential for adaptation between now and then. However, Fig. 7 suggests that the frequency of exceedance of the farm cap of $12 \mathrm{MI} \mathrm{ha}^{-1}$ will have doubled or tripled from the current level of $5 \%$ by 2030. Therefore, some form of adaptation is likely to be required by the next generation of farmers.

By 2050, a second generation of farmers may be dealing with a situation where the farm cap is being exceeded $30 \%$ of the time, requiring a much greater level of adaptation. A third generation, at about 2070, will be approaching the limit of adaptation (as assumed by this example) set by the critical threshold.

Mitigation can be carried out to reduced levels of greenhouse gas to avoid such critical thresholds. However, the impetus for mitigation will not come from one or two critical thresholds identified on a regional basis but from parties to the FCCC who identify 'dangerous' climate change as a threat and seek to forge agreements mitigating against it. This will require integrated assessment on both a regional basis and between regions to assess the balance between critical impacts and possible benefits. For this to occur, methodologies that link critical thresholds to a level of climate change need to be developed, adopted and widely used.

\section{DISCUSSION}

In this paper, ranges of uncertainty for the emission scenarios IS92a-f, global warming from IPCC (1996a) and regional warming for northern Victoria (CSIRO 1996) have been incorporated, along with a $100 \mathrm{yr}$ sequence of daily temperature and rainfall, to allow

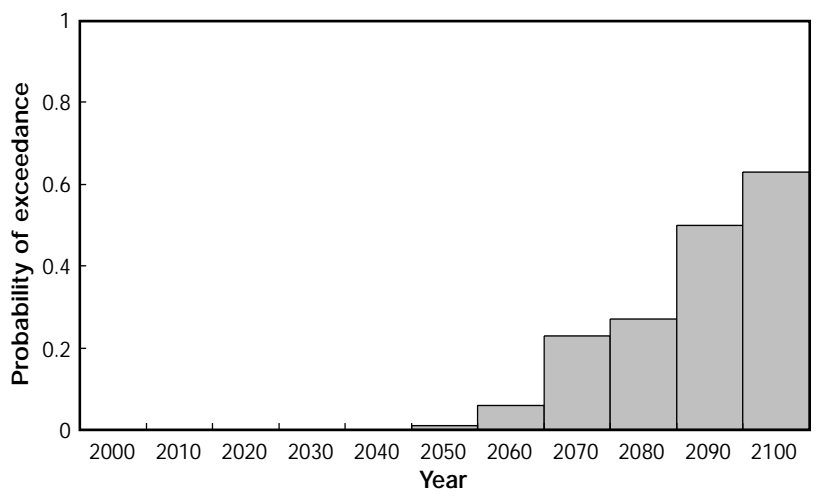

Fig. 8. Probability of exceeding the critical threshold (exceeding the farm cap in $50 \%$ of all years) over time 
for interannual variability. However, the conditions for sampling listed in Section 2.1 have not been fully met. As Visser et al. (1999) point out, global warming projections from IPCC (1996a) do not contain ranges of uncertainty of greenhouse gas mixing or the radiative forcing of greenhouse gases and sulphate aerosol. New emission scenarios commissioned by the IPCC, the SRES (Special Report on Emissions Scenarios) scenarios (Nakicenovic 1998), are a significant improvement on the IS92a-f scenarios but will create a new range of warmings.

Improved methods of sampling, incorporating regional dependencies between temperature and rainfall (Hulme \& Brown 1998, Hulme \& Carter 1999), offer potential for reducing the uncertainties within probabilistic scenarios. Explicit projections for potential evaporation that independently relate potential evaporation to changes in rainfall and temperature are also needed for studies with a hydrological component.

Although based on field data and realistic farmer behaviour, the model presented above cannot be used for forecasting climate impacts on irrigation agriculture unless certain improvements can be added. For instance, the following factors will impact on irrigation demand at the paddock scale: (1) Carbon dioxide fertilisation will tend to increase productivity per unit of water supplied. This increased efficiency in water is unlikely to result in lower net transpiration and higher soil moisture as farmers endeavour to maximise pasture production. (2) Evapotranspiration is not likely to maintain its current relationship with maximum temperature during climate change, as is assumed here. (3) The supply side of the model has not been addressed. Changes to seasonal irrigation supply during droughts may lead to water restrictions and reduced farm caps. Drought frequency is also sensitive to climate change.

Allowing for the above factors would require a crop or pasture model coupled to a soil-moisture model, explicit projections of evapotranspiration and a watersupply model. Longer sequences of historical climate data and improvements to weather generators may improve the realisation of interannual variability.

Economics will also play an important part in the future of such enterprises. There is a trade-off between higher pasture production levels and increased evaporative demand due to $\mathrm{CO}_{2}$ fertilisation. How this tradeoff is realised will be due to factors such as water prices and economic yield at the farm gate in addition to the biophysical aspects just mentioned. The issue of choosing a realistic critical threshold for irrigation demand based on biophysical and economic criteria would also need to be addressed. Kenny et al. (1999) point out that the derivation of management thresholds is not a simple task that requires integrated assessment.
However, the assessment of probabilities for the exceedance of a rule of thumb threshold, or a heuristic threshold set by stakeholders, may indicate whether further, more resource-intensive investigation is warranted.

The recent capping of water rights is changing the way most irrigators in Victoria and much of $\mathrm{New}$ South Wales operate. They can no longer operate simply by evaporative demand as shown in Fig. 3, as the gradually increasing use of irrigation water over time has placed the health of the entire Murray-Darling system at risk (MWEC 1997). Capping water rights will make irrigators much more vulnerable to evaporative demand than they have been in the past, especially during years when water shortages reduce their allocations. Irrigators will need to adapt to the new conditions, by tying increased productivity to units of water use (G. O. J ones pers. comm.). These adaptations are likely to be compatible with the adaptations required to allow for increased irrigation demand under climate change. However, the modelling of irrigation supply under climate change is critical if this assumption is to be tested.

\section{CONCLUSION}

The purpose of this paper is to describe a method of risk analysis for calculating the conditional probabilities of exceeding an impact threshold under climate change. This is a major step forward from more limited assessments of sensitivity and vulnerability, moving impact assessment towards the goal of forecasting specific impacts under expected climate change. While this is a desirable step, many difficulties still need to be overcome. The following caveats apply to the general method used: (1) The probabilities for exceedance of the critical threshold produced by this method (Fig. 8) are conditional probabilities, since they are based on limited ranges of uncertainty. (2) When conducting a risk analysis the full range of quantifiable uncertainty, or a comprehensive range with adequate justification, should be used. Uncertainties that are known and not yet quantifiable or that may be fundamentally unquantifiable should be acknowledged. (3) Default assumptions of probability should be avoided. Every step should be described, making relationships of statistical (in)dependence and probability distribution functions explicit.

This paper shows that by expressing impact thresholds as functions of key climatic variables it is possible to manage many of the uncertainties associated with projected regional climate change through the analysis of conditional probabilities. The example used is one of irrigation demand, where the probability of a 
critical threshold being exceeded was assessed for $10 \mathrm{yr}$ intervals between 2000 and 2100. It was found that the probability of the farm cap being exceeded 1 year in every 2 was $1 \%$ at 2050 increasing to $60 \%$ at 2100 .

This opens a window of adaptation, where an environment of increasing demand needs to be balanced with recent regulatory changes that have capped water rights for individual farmers. Further research is needed to determine how irrigation farmers can best adapt under current climate, and to assess links between these adaptations and those that may be best suited for adapting to climate change.

Three further projects are continuing the work described here. The first, assessing the risk to irrigation supply, is being undertaken for the Macquarie River, a catchment of the Murray-Darling Basin in eastern Australia. The second is assessing communication links between stakeholders and impact researchers in order to utilise the risk assessment framework presented here in a pilot integrated impact assessment in the Hunter Valley, on the central eastern coast of Australia. The third is constructing probabilistic climate change projections for a number of climatic variables, including potential evaporation and decadal-scale rainfall variability, for use by Australian impact researchers. A risk assessment framework involving both researchers and stakeholders, and utilising the example of risk analysis described here, describes how impact thresholds and key climatic variables can be related and assessed to treat risk through adaptation measures.

Acknowledgements. This paper is based on a presentation to a workshop on the impacts of global change on Australian temperate forests in Canberra in February 1998. I would like to thank my parents, Gyn and Elaine Jones, for data and management records from the Model Farm, Kerang, and for the valuable discussions about irrigation practises and farm management that allowed the irrigation demand model to be built. Drs Barrie Pittock and Peter Whetton and Mr Barrie Hunt as well as 3 anonymous reviewers provided valuable suggestions for the manuscript. Dr Mikhail Semenov and the Long Ashton Research Station, University of Bristol, are acknowledged for the use of the LARS-WG artificial weather generator. This work is part of the Climate Impact and Adaptation Liaison Project, funded by Environment Australia.

\section{LITERATURE CITED}

Bernstein PL (1996) Against the Gods: the remarkable story of risk. J Wiley and Sons, New York

Boughton WC (1966) A mathematical model for relating runoff to rainfall with daily data. Civil Eng Trans IE Aust 8: 83-97

Campbell BD, Stafford Smith DM, McKeon GM (1997) Elevated $\mathrm{CO}_{2}$ and water supply interactions in grasslands: a pastures and rangelands management perspective. Global
Change Biol 3:177-187

Cox W, Baxter P (1996) Setting the cap: report of the independent audit group. Murray-Darling Ministerial Council, Canberra

CSIRO (1992) Climate change scenarios for the Australian Region. Climate Impact Group, CSIRO Division of Atmospheric Research, Melbourne

CSIRO (1996) Climate change scenarios for the Australian Region. Climate Impact Group, CSIRO Division of Atmospheric Research, M elbourne

Hassall \& Associates (eds) (1998) Climate change scenarios and managing the scarce water resources of the Macquarie River. Australian Greenhouse Office, Canberra

Henderson-Sellers A (1993) An Antipodean climate of uncertainty. Clim Change 25:203-224

Hulme M, Brown O (1998) Portraying climate scenario uncertainties in relation to tolerable regional climate change. Clim Res 10:1-14

Hulme M, Carter TR (1999) Representing uncertainty in climate change scenarios and impact studies. In: Carter TR, Hulme M, Viner D (eds) Representing uncertainty in climate change scenarios and impact studies. Proceedings of the ECLAT-2 Helsinki Workshop, 14-16 April, 1999, Climatic Research Unit, Norwich, p 11-37

IPCC (1996a) Technical summary. In: Houghton JT, Meira Filho LG, Callander BA, Harris N, Kattenberg A, Maskell K (eds) Climate change 1995: the science of climate change. Contribution of Working Group I to the second assessment report of the Intergovernmental Panel on Climate Change. Cambridge University Press, Cambridge, p 9-49

IPCC (1996b) Technical summary. In: Watson RT, Zinyowera MC, M oss RH (eds) Climate change 1995: impacts, adaptations and mitigation of climate change: scientific-technical analyses. Contribution of Working Group II to the second assessment report of the Intergovernmental Panel on Climate Change. Cambridge University Press, Cambridge, p 19-53

J ones RN (1997) Milestone 14, Potential impact of climate change on runoff and water availability for irrigation, Report to the Rural Industry Research and Development Corporation. CSIRO Division of Atmospheric Research, Melbourne

J ones RN (1999) Managing uncertainty in climate change projections-issues for impact assessment. Clim Change (in press)

J ones RN, Pittock AB (1997) Assessing the impacts of climate change: the challenge for ecology. In: Klomp N, Lunt I (eds) Frontiers in ecology: building the links. Elsevier Science Ltd, Amsterdam, p 311-322

Kenny GJ , Warrick RA, Campbell BD, Sims GC, Camilleri M, J amieson PD, Mitchell ND, McPherson HG, Salinger MJ (1999) Investigating climate change impacts and thresholds: an application of the CLIM PACTS integrated assessment model for New Zealand agriculture. Clim Change (in press)

Knutson KR, Manabe S, Gu D (1997) Simulated ENSO in a global coupled ocean-atmosphere model: multidecadal amplitude and $\mathrm{CO}_{2}$ sensitivity. J Clim 10:138-161

Mahlman J D (1997) Uncertainties in projections of humancaused climate warming. Science 278:1416-1417

MWEC (1997) Sharing the Murray: proposal for defining people's entitlements to Victoria's water from the Murray. Murray Water Entitlement Committee, Melbourne

Nakicenovic N (1998) Draft discussion paper. IPCC Special Report on Emissions Scenarios (SRES). Center for International Earth Science Information Network, Columbia Uni- 
versity (accessed: 15 December 1999); available at: http:// sres.ciesin.org/sres/htmls/prg_report.html

Parry ML, Carter TR, Hulme M (1996) What is a dangerous climate change? Global Environ Change 6:1-6

Pittock AB (1993) Climate scenario development. In: J akeman AJ, Beck MB, McAleer MJ (eds) Modelling change in environmental systems. J ohn Wiley \& Sons, Chichester, p 481-503

Pittock AB, J ones RN (1999) Adaptation to what, and why? Environ Monit Assess (in press)

Racsko P, Szeidl L, Semenov MA (1991) A serial approach to local stochastic weather models. Ecol Model 57:27-41

Rotmans J, Hulme M, Downing TE (1994) Climate change implications for Europe: an application of the ESCAPE model. Global Environ Change 4:97-124

Santer BD, Wigley TM L, Schlesinger ME, M itchell J FB (1990) Developing climate scenarios from equilibrum GCM results. Report No. 47, Max Planck Institute for M eterology, Hamburg

Schreider SYu, Jakeman AJ, Pittock AB, Whetton PH (1996) Estimation of possible climate change impacts on water

Editorial responsibility: Mike Hulme,

Norwich, United Kingdom availability, extreme flow events and soil moisture in the Goulburn and Ovens Basins, Victoria. Clim Change 34: 513-546

Semenov MA, Brooks RJ , Barrow EM, Richardson CW (1998) Comparison of the WGEN and LARS-WG stochastic weather generators for diverse climates. Clim Res 10:95-107

Timmermann A, Oberhuber J, Bacher A, Esch M, Latif M, Roeckner E (1999) Increased EI Niño frequency in a climate model forced by future greenhouse warming. Nature 398:694-697

Visser H, Folkert RJ M , Hoekstra J , de Wolff J J (1999) Identifying key sources of uncertainty in climate change projections. Clim Change (in press)

Whetton PH, Haylock M R, Galloway R (1996) Climate change and snow-cover duration in the Australian Alps. Clim Change 32:447-479

Wilson SG, Hunt BG (1997) Impact of greenhouse warming on EI Niño/Southern Oscillation behaviour in a high resolution coupled global climatic model. Report to Environment Australia, CSIRO Division of Atmospheric Research, Melbourne

Submitted: J uly 6, 1999; Accepted: November 1, 1999

Proofs received from author(s): J anuary 18, 2000 